\title{
Quantitative trait locus analysis of heterosis for plant height and ear height in an elite maize hybrid zhengdan 958 by design III
}

\author{
Hongjian Li ${ }^{1}$, Qingsong Yang ${ }^{1,2}$, Nannan Fan ${ }^{1,2}$, Ming Zhang ${ }^{1}$, Huijie Zhai ${ }^{1}$, Zhongfu Ni ${ }^{1}$ and Yirong Zhang ${ }^{1,2^{*}}$
}

\begin{abstract}
Background: Plant height $(\mathrm{PH})$ and ear height $(\mathrm{EH})$ are two important agronomic traits in maize selection breeding. $\mathrm{F}_{1}$ hybrid exhibit significant heterosis for $\mathrm{PH}$ and $\mathrm{EH}$ as compared to their parental inbred lines. To understand the genetic basis of heterosis controlling PH and EH, we conducted quantitative trait locus (QTL) analysis using a recombinant inbreed line (RIL) based design III population derived from the elite maize hybrid Zhengdan 958 in five environments.
\end{abstract}

Results: A total of 14 environmentally stable QTLs were identified, and the number of QTLs for $Z_{1}$ and $Z_{2}$ populations was six and eight, respectively. Notably, all the eight environmentally stable QTLs for $Z_{2}$ were characterized by overdominance effect (OD), suggesting that overdominant QTLs were the most important contributors to heterosis for $\mathrm{PH}$ and EH. Furthermore, 14 environmentally stable QTLs were anchored on six genomic regions, among which four are trait-specific QTLs, suggesting that the genetic basis for PH and EH is partially different. Additionally, qPH.A-1.3, modifying about 10 centimeters of $\mathrm{PH}$, was further validated in backcross populations.

Conclusions: The genetic basis for PH and EH is partially different, and overdominant QTLs are important factors for heterosis of PH and EH. A major QTL QPH.A-1.3 may be a desired target for genetic improvement of maize plant height.

Keywords: Heterosis, Plant height, Ear height, Design III, Maize

\section{Background}

Maize is one of the most important crops worldwide, which serves as food, animal feed and raw materials of bioenergy. Plant height $(\mathrm{PH})$ and ear height $(\mathrm{EH})$ are two main selection factors in maize architecture because optimal $\mathrm{PH}$ and $\mathrm{EH}$ are critical for improving plant density to maximize the utilization of fertilizer, moisture and incident photosynthetically active radiation [1-3]. More than 40 maize dwarf genes for $\mathrm{PH}$ have been cloned in maize so far, which were reported to be related to various biosynthesis pathways [4-12]. However, these mutants have less potential applications in maize breeding because of their harmful impacts on grain yield [13]. An alternative strategy is to identify moderate alleles (QTLs) reducing plant height, which may be feasible and effective. Since the first publication of molecular linkage

\footnotetext{
* Correspondence: zhangyr@cau.edu.cn

${ }^{1}$ State Key Laboratory for Agrobiotechnology and Key Laboratory of Crop Heterosis Utilization (MOE), China Agricultural University, Beijing 100193, China ${ }^{2}$ National Maize Improvement Center of China, China Agricultural University, Beijing 100193, China
} height have been reported [14-17]. Wang et al. integrated QTLs for plant height and ear height based on the target map IBM2 2008 Neighbors. They found several GA pathway genes were located in the meta-QTL region [18]. Xing et al. cloned a major plant height QTL-qph1, which contains a naturally occurring rare SNP in $b r 2$. qph1 reduced plant height and ear height with no or very little negative impact on yield when heterozygous [19]. $Z m G A 3 o x 2$, which is a candidate gene for a major QTL-qPH3.1, was also reported to modify approximately $10 \%$ of the total plant height without influence on grain yield, yield-associated traits or flowering time [20]. The identification of more QTLs/genes related to the two traits might facilitate our understanding of the genetic mechanism of height development and beneit future maize improvement.

The superior performance of $F_{1}$ hybrid over its parental lines was defined as heterosis, which has been led to great success in plant breeding $[13,21]$. Maize PH and EH exhibit significant heterosis and can be easily and 
accurately measured [22-25]. Thus, QTL mapping of heterotic loci for the two traits has attracted much attention. Up to date, design III and triple testcross design (TTC) are most commonly used experimental designs for estimating the average degree of dominance or overdominance of quantitative genes. Design III populations were constructed using $F_{n}$ plants from a cross between two inbreds to back-crossed with the inbred parents, while TTC populations were constructed using $F_{n}$ plants from a cross between two inbreds to back-crossed with the inbred parents and the hybrid [23, 26]. Stuber et al. did pioneering work in maize to identify QTLs related to heterosis with the aid of molecular markers. They concluded that overdominance (or pseudo-overdominance) was the main cause of heterosis for $\mathrm{PH}$ and $\mathrm{EH}$ [27]. Nevertheless, Cockerham and Zeng showed that dominance of favorable alleles together with epistatic between linked QTLs played important roles in the phenomenon of heterosis by reanalyzing Stuber's data using design III [28]. Using a random-mated maize population, Lu et al. concluded that most of the QTLs for PH showed partial to complete dominance [25]. Frascaroli et al. studied heterosis underlying $\mathrm{PH}$ with the utilization of a triple testcross design (TTC) population and demonstrated that heterosis in the maize hybrid B73 $\times$ H99 was mainly due to dominance at various levels, with epistasis playing a less important role [23]. Also, Song et al. emphasized the predominance of overdominant QTLs for $\mathrm{PH}$ and $\mathrm{EH}$, and they found three important heterotic regions for the two traits [22]. Although such studies have been reported, the ever changing conclusions of genetic basis underlying heterosis for maize $\mathrm{PH}$ and $\mathrm{EH}$ suggested that more investigations should be conducted.

The maize hybrid Zhengdan 958 is one of the most popular hybrids in China, which contributed about 20\% of total maize production [29]. However, studies on heterosis for $\mathrm{PH}$ and $\mathrm{EH}$ of this hybrid were rarely reported. In the present study, we used a design III population from the hybrid Zhengdan 958 to analyze QTLs associate with heterosis. Our objectives were: 1 ) to assess the level of heterosis for PH and EH; 2) to detect the QTLs and evaluate their effects related to heterosis; 3 ) to validate QTL-qPH.A-1.3 in backcross populations.

\section{Method}

\section{Plant materials and field experiments}

A total of 162 RILs derived from the hybrid Zhengdan 958 (Zheng $58 \times$ Chang $7-2$ ), were crossed with its two parents following the design III [23, 26]. In brief, 162 RILs $\left(F_{7}\right)$ derived from the hybrid Zhengdan 958 were used as pollen parents to cross the parental lines Zheng 58 [TC (Zheng 58)] and Chang 7-2 [TC (Chang 7-2)] (Fig. 1). The two populations of TC progeny along with other materials (i.e., the parental lines, Zhengdan 958

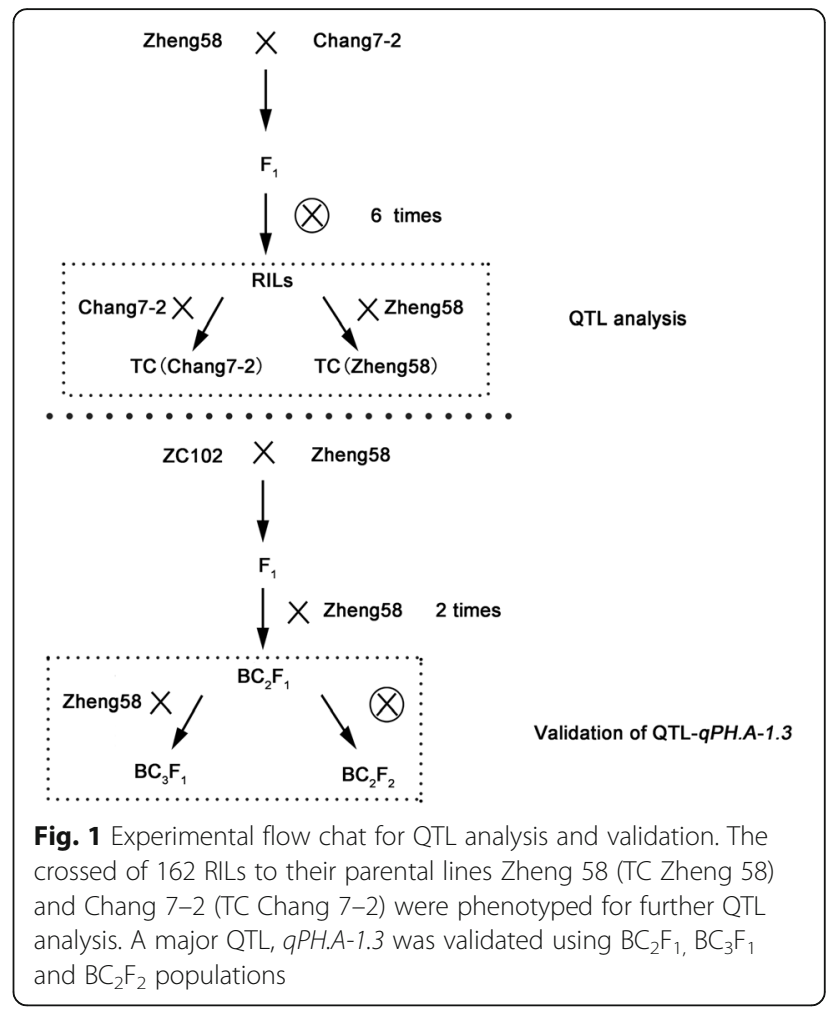

and RILs) were field-tested in five environments in China with three replications per location. Location-year information and climate data across the whole life cycle are presented in Additional file 1. Field management policies followed local standard practices.

The RIL line ZC102, which was homologous with the parental line Chang7-2 at the QTL-qPH.A-1.3 region and shared $74 \%$ of the same genetic background with parental line Zheng 58, was chosen as the donor line to cross with Zheng 58 with marker assisted selection. In 2014, 350 $\mathrm{BC}_{2} \mathrm{~F}_{1}$ plants were genotyped and field tested in Jilin province. Several heterozygous plants were self-pollinated or back crossed with Zheng 58 to produce $\mathrm{BC}_{2} \mathrm{~F}_{2}$ and $\mathrm{BC}_{3} \mathrm{~F}_{1}$ populations. In the winter of 2014, $217 \mathrm{BC}_{2} \mathrm{~F}_{2}$ and 161 $\mathrm{BC}_{3} \mathrm{~F}_{1}$ individuals were planted in Hainan.

$\mathrm{PH}$ was scored as the distance from the soil line of the plant to the top of the tassel, and EH was measured as the distance from the soil to the primary ear node.

\section{Data analysis}

Mid-parent heterosis $(\mathrm{MPH})$ was used to score the percentage of heterosis: $\mathrm{MPH}=\left(\mathrm{F}_{1}-\mathrm{MP}\right) / \mathrm{MP} \times 100$, where MP represented the mid-parent value. Following the methods reported by Comstock et al. [26] and Melchinger et al. [30], the crosses of RILs to their parental lines Zheng 58 (TC Zheng 58) and Chang 7-2 (TC Chang 7-2) were denoted as $\mathrm{L}_{1 \mathrm{i}}$ and $\mathrm{L}_{2 \mathrm{i}}(\mathrm{i}=1 \sim 162)$, respectively. The linear transformations were $\mathrm{Z}_{1 \mathrm{i}}=\left(\mathrm{L}_{1 \mathrm{i}}+\mathrm{L}_{2 \mathrm{i}}\right) / 2$ and $\mathrm{Z}_{2 \mathrm{i}}=\mathrm{L}_{2 \mathrm{i}}-\mathrm{L}_{1 \mathrm{i}}$. $\mathrm{A}$ combined ANOVA over five environments was calculated 
to estimate variance components. Additive Variances $\left(V_{A}\right)$ within $\mathrm{Z}_{1}$ and dominance variances $\left(V_{D}\right)$ within $\mathrm{Z}_{2}$ were used to score the average degree of dominance $D^{*}$ as $\left(V_{D} /\right.$ $\left.2 V_{A}\right)^{0.5}$, which stood for the degree of dominance over all separating loci $[23,28,30]$.

The best linear unbiased prediction (BLUP) values across five environments were computed with the PROC MIXED procedure in SAS (SAS Institute Inc., North Carolina, USA). Broad-sense heritability $\left(h_{B}^{2}\right)$ were estimated as $h_{B}^{2}=\sigma_{g}^{2} /\left(\sigma_{g}^{2}+\sigma_{g e}^{2} / n+\sigma^{2} / n r\right)$, where $\sigma_{g}^{2}$ is the genetic variance, $\sigma_{g e}^{2}$ is the genotype by environment interaction variance, $\sigma^{2}$ is the error variance, $n$ is the number of environments, and $r$ is the number of replications of each experiment [31, 32]. Correlation coefficients among $\mathrm{PH}$ and $\mathrm{EH}$ were estimated using adjusted mean values for $Z_{1}$ and $Z_{2}$.

\section{Genotyping and linkage analyses}

The RIL population was genotyped using a Maize SNP50 BeadChip [33]. A genetic linkage map was constructed using MSTMap software [34].In brief, a total of 905 SNP markers were mapped in the genetic linkage map with an average of $2.65 \mathrm{cM}$ between adjacent markers, spanning $2402.0 \mathrm{cM}$ (Additional file 7).

\section{QTL Analysis}

For each $Z_{s}(s=1,2)$ population, the mean of three replications in a single location were used for QTL analysis. The BLUP values across five environments were used for combined analysis. QTL analysis was performed through the composite interval mapping (CIM) using Windows QTL Cartographer version 2.5 [35, 36]. A test of 1,000 permutations was adopted to determine the thresholds for the logarithm of odds (LOD) scores of putative QTLs [32]. QTLs in $Z_{1}$ and $Z_{2}$ reflect the augmented additive effects $a_{i}{ }^{*}$ and augmented dominance effects $d_{i}{ }^{*}$, respectively [30]. The dominance degree ratios were estimated as $\left|d_{i}{ }^{*} / a_{i}{ }^{*}\right|=$ augmented dominance effects/augmented additive effects: A, additive $\left(\left|d_{i}{ }^{*} / a_{i}{ }^{*}\right| \leq 0.20\right)$; PD, partial dominance $\left(0.20<\left|d_{i}{ }^{*} / a_{i}{ }^{*}\right|\right.$ $<0.80)$; D, dominance $\left(0.80 \leq\left|d_{i}{ }^{*} / a_{i}{ }^{*}\right|<1.20\right)$; and OD, overdominance $\left(\left|d_{i} * / a_{i}{ }^{*}\right| \geq 1.20\right)$. QTL were congruent with overlapping confidence intervals across environments for a given trait.

\section{SSR maker development}

The stable QTL-qPH.A-1.3 was identified between SNP markers SNP5629 and SNP6190. Sequence information in this region was obtained from the maize sequence database (http://www.maizesequence.org/) to develop new markers. The sequences were scanned using the software SSRHunter1.3 [37] to detecte simple-sequence repeats (SSRs). Primers were designed by PRIMER 5.0 or PRIMER 3 (http://frodo.wi.mit.edu/primer3/) [38]. SSR primers appeared polymorphic between two parental lines were used for marker associated selection and genotyping of each plant in the $\mathrm{BC}_{2} \mathrm{~F}_{1}, \mathrm{BC}_{3} \mathrm{~F}_{1}$ and $\mathrm{BC}_{2} \mathrm{~F}_{2}$ populations.

\section{Results}

\section{Heterosis and population performance}

The average field performance and heterosis of $\mathrm{PH}$ and $\mathrm{EH}$ for the basic populations are listed in Table 1. Chang 7-2 had higher $\mathrm{PH}$ and $\mathrm{EH}$ than Zheng 58 in all the five environments $(P<0.01)$. Compared to parental lines, the hybrid Zhengdan 958 showed overwhelming superiority in each environment, with heterosis ranged from $25.27 \%$ to $40.32 \%$ for $\mathrm{PH}$ and from $25.7 \%$ to $43.94 \%$ for $\mathrm{EH}$.

The minimum, maximum, mean values of TC populations for each trait are shown in Table 2. With respect to $\mathrm{TC}$ progenies, the average performance of TC (Chang 7-2) were significantly higher than TC (Zheng 58 ) for both $\mathrm{PH}$ and $\mathrm{EH}(P<0.01)$, which is consistent with the observation of parental lines Chang 7-2 and Zheng 58. Correlation

Table 1 Performance of the basic generations (the parental line Zheng 58, Chang 7-2 and the hybrid Zhengdan 958) and heterosis for plant height (PH) and ear height (EH) in five environments

\begin{tabular}{|c|c|c|c|c|c|c|}
\hline Trait & Environment & Zheng58 & Chang7-2 & MP & $\mathrm{F}_{1}$ & MPH (\%) \\
\hline \multirow[t]{5}{*}{$\mathrm{PH}$} & E1 & $183.19 \pm 10.03$ & $199.86 \pm 8.47^{* *, a}$ & 191.52 & $268.75 \pm 12.61^{* *, b}$ & $40.32^{c}$ \\
\hline & E2 & $148.28 \pm 11.40$ & $175.32 \pm 11.93^{* *}$ & 161.80 & $209.67 \pm 9.84^{* *}$ & 29.59 \\
\hline & E3 & $175.37 \pm 7.88$ & $205.21 \pm 11.97^{* *}$ & 190.29 & $247.20 \pm 12.77^{* *}$ & 29.91 \\
\hline & E4 & $161.19 \pm 7.63$ & $210.50 \pm 6.27^{* *}$ & 185.84 & $247.97 \pm 8.57^{* *}$ & 33.43 \\
\hline & E5 & $180.52 \pm 8.36$ & $215.01 \pm 6.88^{* *}$ & 197.77 & $247.75 \pm 6.96^{* *}$ & 25.27 \\
\hline \multirow[t]{5}{*}{$\mathrm{EH}$} & E1 & $68.90 \pm 7.95$ & $102.81 \pm 10.25^{* *}$ & 85.86 & $123.58 \pm 10.04^{* *}$ & 43.94 \\
\hline & E2 & $45.63 \pm 3.86$ & $84.03 \pm 6.09^{* *}$ & 64.83 & $86.73 \pm 7.72^{* *}$ & 33.78 \\
\hline & E3 & $61.14 \pm 6.65$ & $101.26 \pm 9.40^{* *}$ & 81.20 & $114.26 \pm 8.28^{* *}$ & 40.71 \\
\hline & E4 & $51.07 \pm 5.65$ & $101.13 \pm 2.86^{* *}$ & 76.10 & $105.56 \pm 4.84^{* *}$ & 38.71 \\
\hline & E5 & $61.41 \pm 5.57$ & $104.43 \pm 6.43^{* *}$ & 82.92 & $104.23 \pm 5.98^{* *}$ & 25.70 \\
\hline
\end{tabular}

${ }^{* *} P \leq 0.01$

${ }^{\mathrm{a} C}$ Comparison between Zheng 58 and Chang 7-2 using $t$ test; ${ }^{\mathrm{b}}$ Comparison between midparent $(\mathrm{MP})$ and $\mathrm{F}_{1}$ using $t$ test, ${ }^{\mathrm{c}}$ Mid-parent heterosis $(\mathrm{MPH})$ : $\left(\mathrm{F}_{1}-\mathrm{MP}\right) / \mathrm{MP} \times 100$ 
Table 2 Performance of plant height (PH) and ear height (EH) for TC (Zheng 58) and TC (Chang 7-2) in five environments

\begin{tabular}{|c|c|c|c|c|c|c|}
\hline \multirow[t]{2}{*}{ Population } & \multirow[t]{2}{*}{ Phenotypic data } & \multicolumn{5}{|c|}{$\underline{\text { Environment }}$} \\
\hline & & E1 & E2 & E3 & E4 & E5 \\
\hline & & & & $\mathrm{PH}$ & & \\
\hline \multirow[t]{3}{*}{ TC(Zheng 58) } & Mean $(\mathrm{cm})$ & 238.80 & 187.61 & 226.48 & 221.29 & 225.55 \\
\hline & $\operatorname{Max}(\mathrm{cm})$ & 275.48 & 235.24 & 270.47 & 259.83 & 264.5 \\
\hline & $\operatorname{Min}(\mathrm{cm})$ & 196.43 & 158.47 & 178.4 & 187.79 & 185.78 \\
\hline \multirow[t]{4}{*}{ TC(Chang 7-2) } & Mean $(\mathrm{cm})$ & $248.75^{* * a}$ & $210.02^{* *}$ & $243.81^{* *}$ & $243.32^{* *}$ & $244.12^{* *}$ \\
\hline & $\operatorname{Max}(\mathrm{cm})$ & 297.38 & 242.29 & 279.2 & 283.13 & 274.67 \\
\hline & $\operatorname{Min}(\mathrm{cm})$ & 204.29 & 175.91 & 207.07 & 187.5 & 206.72 \\
\hline & & & & $\mathrm{EH}$ & & \\
\hline \multirow[t]{4}{*}{ TC(Zheng 58) } & Mean $(\mathrm{cm})$ & 94.85 & 68.99 & 93.93 & 85.17 & 85.97 \\
\hline & $\operatorname{Max}(\mathrm{cm})$ & 125.00 & 107.52 & 117.57 & 112.75 & 110.61 \\
\hline & $\operatorname{Min}(\mathrm{cm})$ & 72.38 & 50.03 & 64.23 & 63.96 & 66.89 \\
\hline & $r$ & $0.82^{* *}$ & $0.78^{* *}$ & $0.85^{* *}$ & $0.82^{* *}$ & $0.84^{* *}$ \\
\hline \multirow[t]{4}{*}{ TC(Chang 7-2) } & Mean $(\mathrm{cm})$ & $121.77^{* *}$ & $94.36^{* *}$ & $119.44^{* *}$ & $115.19^{* *}$ & $110.42^{* *}$ \\
\hline & $\operatorname{Max}(\mathrm{cm})$ & 151.67 & 118.71 & 141.17 & 163.38 & 132.83 \\
\hline & $\operatorname{Min}(\mathrm{cm})$ & 85.95 & 79.84 & 89.17 & 90.63 & 86.33 \\
\hline & $r$ & $0.71^{* *}$ & $0.71^{* *}$ & $0.80^{* *}$ & $0.71^{* *}$ & $0.83^{* *}$ \\
\hline
\end{tabular}

${ }^{* *} P \leq 0.01$

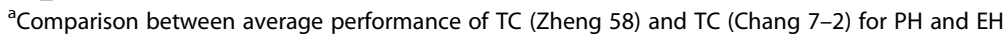

$r$ : Correlation between $\mathrm{PH}$ and $\mathrm{EH}$ in each population

coefficients among $\mathrm{PH}$ and $\mathrm{EH}$ within TC populations were also tested. Interestingly, PH was positively correlated with EH in each TC population. Notably, drought stress could significantly decrease maize plant height [39]. The total precipitation in May of 2012 was extremely lower and no irrigation is given in time in E2, which may lead to the lowest plant height in $\mathrm{F}_{1}$ and $\mathrm{TC}$ populations.

Variance analysis of $\mathrm{Z}_{1}$ and $\mathrm{Z}_{2}$ revealed that $V_{A}$ and $V_{D}$ for $\mathrm{PH}$ and $\mathrm{EH}$ were significant $(P<0.01)$ (Table 3). We calculated the average degree of dominance $\left(D^{*}\right)$ for each trait. The results showed that the $D^{*}$ was 0.83 for $\mathrm{PH}$ and 0.71 for EH. In addition, broad sense heritability $\left(h_{B}^{2}\right)$ was high for $\mathrm{PH}$ and $\mathrm{EH}$ in both $\mathrm{Z}_{1}$ and $\mathrm{Z}_{2}(0.77 \sim 0.94)$.

Table $3 V_{A}, V_{D}$, broad sense heritability $\left(h_{B}^{2}\right)$ and average degree of dominance $\left(D^{*}\right)$ for $Z_{1}$ and $Z_{2}$ across five environments

\begin{tabular}{llll}
\hline Linear transformations & Parameter & Trait & \\
\cline { 3 - 4 } & & PH & EH \\
\hline$Z_{1}$ & $V_{A}^{A}$ & $1543.45^{* *}$ & $762.28^{* *}$ \\
& $h_{B}^{2}$ & 0.94 & 0.94 \\
& $\mathrm{Cl}\left(h_{B}^{2}\right)^{c}$ & $(0.93,0.95)$ & $(0.92,0.95)$ \\
& $V_{D}^{0}$ & $2134.61^{* *}$ & $769.06^{* *}$ \\
$Z_{2}$ & $h_{B}^{2}$ & 0.86 & 0.77 \\
& $C l\left(h_{B}^{2}\right)$ & $(0.83,0.89)$ & $(0.72,0.81)$ \\
& $D^{*}$ & 0.83 & 0.71 \\
\hline
\end{tabular}

${ }^{*} P \leq 0.05 ;{ }^{* *} P \leq 0.01$

additive variance; ${ }^{\mathrm{b}}$ dominance variance; ${ }^{\mathrm{c}} 95 \%$ confidence interval
Remarkably, the $h_{B}^{2}$ was higher in $Z_{1}$ than that in $Z_{2}$ for $\mathrm{PH}$ and $\mathrm{EH}$.

\section{Mapping environmentally stable $Q T L s$ for $Z_{1}$ and $Z_{2}$}

A total of 111 QTL were detected for $\mathrm{PH}$ and $\mathrm{EH}$ in the maize hybrid Zhengdan 958 (Additional file 2). In the present study, a QTL identified within two or more environments as well as in the combined analysis was regarded as "environmentally stable QTL". As a result, 14 environmentally stable QTLs were detected, which distributed on chromosomes 1, 5, 8 and 9 (Fig. 2 and Table 4).

Fifty-six QTLs associated with $\mathrm{PH}$ were detected. Nine environmentally stable QTLs for PH were identified on chromosomes $1,5,8$ and 9, which were designated qPH.A-1.2, qPH.A-1.3, qPH.A-1.4, qPH.B-1.2, qPH.B-1.3, $q$ PH.B-5.3, qPH.B-8.2, qPH.B-9.2 and qPH.B-9.3, respectively. Parental line Chang 7-2 contributed PD effect for the increased PH of $q P H . A-1.2$ and $q P H . A-1.3$, as well as A effect for the increased PH of $q P H . A-1.4$, for the combined analysis. The rest six QTLs showed an OD effect for $\mathrm{Z}_{2}$, which explained from 5.2 to $10.2 \%$ of variation for the combined analysis.

Fifty-five QTLs were found to be associated significantly with $\mathrm{EH}$, and five environmentally stable QTLs were detected on chromosomes 1 and 8 (qEH.A-1.6, qEH.A-1.7, $q E H . A-8.3, q E H . B-1.5$ and $q E H . B-8.2)$. Parental line Chang 7-2 contributed D effect for the increased $\mathrm{EH}$ of $q E H . A$ 1.6 and $q E H . A-1.7$, which explained 7.6 and $8.5 \%$ of 


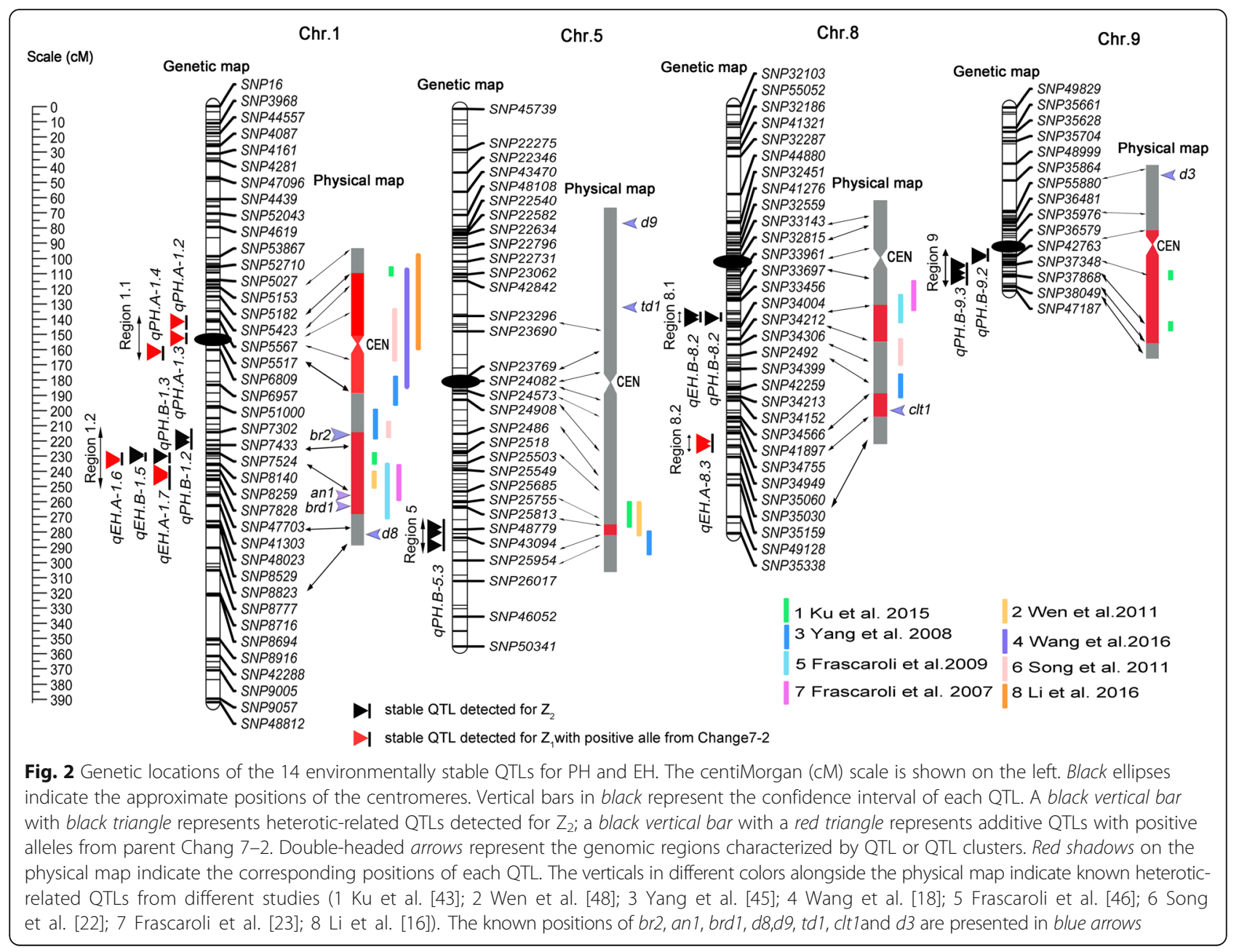

variation for the combined analysis, respectively. In addition, Chang 7-2 contributed increased effects for $q E H . A-8.3$ with additive effect (A) and explained $9.2 \%$ of variation for the combined analysis. Remarkably, $q E H . B-$ 1.5 and $q E H . B-8.2$ exhibited an OD effect for $\mathrm{Z}_{2}$ and explained 8.4 and $9.5 \%$ of variation for the combined analysis, respectively.

Interestingly, the 14 environmentally stable QTLs were anchored on six genomic regions (Fig. 2 and Table 4). Region 1.1 contained three tightly linked QTLs for $\mathrm{PH}$ (qPH.A-1.2, qPH.A-1.3 and qPH.A-1.4), and each of them was detected in $\mathrm{Z}_{1}$. Region 1.2 covered two overdominant QTLs for PH (qPH.B-1.2 and qPH.B-1.3), one overdominant QTL for EH $(q E H . B-1.5)$ and two dominant QTLs for EH (qEH.A-1.6 and $q E H . A-1.7)$. Region 8.1 harbored two overlapped dominant QTLs, with one for $\mathrm{PH}(q P H . B-8.2)$ and the other one for $\mathrm{EH}(q E H . B-8.2)$. Region 9 contained two tightly linked dominant QTLs for $\mathrm{PH}(q P H . B-9.2$ and $q P H . B-9.3)$. In addition, region 5 and region 8.2 mapped a single QTL for PH ( $q P H . B-5.3)$ and $\mathrm{EH}(q E H . A-8.3)$, respectively.

\section{Validation of $q P H . A-1.3$}

$q P H . A-1.3$ could be mapped in four of the five investigated environments and explained a large amount of phenotypic variance (Table 4), which revealed its potential for further study. Thus, we developed ten polymorphic SSR markers to validate the presence of $q P H . A-$ 1.3, and all of them were anchored on the qPH.A-1.3 region based on the RIL population (Additional file 3 and Table 5). Two SSR markers (MPH72 and MPH1149) flanking $q P H . A-1.3$ were used to determine the individual genotypes in $\mathrm{BC}_{2} \mathrm{~F}_{1}, \mathrm{BC}_{3} \mathrm{~F}_{1}$ and $\mathrm{BC}_{2} \mathrm{~F}_{2}$. The genotype which was identical to the Zheng 58 parent was designated $\mathrm{Z} / \mathrm{Z}$, the genotype which was identical to the Chang 7-2 parent was designated $\mathrm{C} / \mathrm{C}$, while the genotype which carried both Zheng 58 and Chang 7-2 parental alleles was designated $\mathrm{Z} / \mathrm{C}$. Of the plants in $\mathrm{BC}_{2} \mathrm{~F}_{1}$ and $\mathrm{BC}_{3} \mathrm{~F}_{1}$, the average $\mathrm{PH}$ of $\mathrm{Z} / \mathrm{C}$ individuals were 6.1 and 5.2 centimeters higher than that of $\mathrm{Z} / \mathrm{Z}$ ( $t$-test, $P=$ 2.93E-05 and $P=0.001$, respectively). While in the $\mathrm{BC}_{2} \mathrm{~F}_{2}$ population, $\mathrm{PH}$ differed significantly ( $F$-test, $P=$ $8.32 \mathrm{E}-06)$ between the three genotypic classes. The 
Table 4 Genomic regions harboring environmentally stable QTL for plant height (PH) and ear height (EH) for $Z_{1}$ and $Z_{2}$

\begin{tabular}{|c|c|c|c|c|c|c|c|c|c|c|c|c|}
\hline \multirow[t]{2}{*}{ 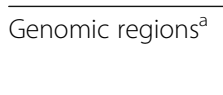 } & \multirow[t]{2}{*}{ Interval (cM) } & \multirow[t]{2}{*}{ Associated traits ${ }^{b}$} & \multirow{2}{*}{$\begin{array}{l}\text { Included } \\
\text { QTL }\end{array}$} & \multicolumn{3}{|l|}{$Z_{1}^{c}$} & \multicolumn{3}{|l|}{$Z_{2}$} & \multirow[t]{2}{*}{ Gene cation $^{d}$} & \multirow{2}{*}{$\begin{array}{l}\text { Detected } \\
\text { environment }\end{array}$} & \multirow[t]{2}{*}{ References $^{f}$} \\
\hline & & & & $\overline{L O D}$ & $a_{i}^{*}$ & $\overline{R^{2}(\%)}$ & $\overline{L O D}$ & $d_{i}^{*}$ & $\overline{R^{2}(\%)}$ & & & \\
\hline \multirow[t]{3}{*}{ Region 1.1} & $137.7-167.4$ & $\mathrm{PH}(+)$ & qPH.A-1.2 & 4.6 & -3.2 & 8.6 & & & & PD & $\mathrm{E} 4, \mathrm{E} 5, \mathrm{C}$ & 1,4 \\
\hline & & $\mathrm{PH}(+)$ & qPH.A-1.3 & 6.3 & -3.8 & 11.5 & & & & PD & $\mathrm{E} 1, \mathrm{E} 3, \mathrm{E} 4, \mathrm{E} 5, \mathrm{C}$ & 4,6 \\
\hline & & $\mathrm{PH}(+)$ & qPH.A-1.4 & 4.6 & -3.2 & 8.5 & & & & A & $\mathrm{E} 4, \mathrm{E} 5, \mathrm{C}$ & $3,4,6,8$ \\
\hline \multirow[t]{5}{*}{ Region 1.2} & 212.6-253.8 & $\mathrm{PH}$ & qPH.B-1.2 & & & & 3.7 & 2.6 & 5.4 & OD & $\mathrm{E} 1, \mathrm{E} 4, \mathrm{C}$ & 3,6 \\
\hline & & $\mathrm{PH}$ & qPH.B-1.3 & & & & 3.6 & 2.5 & 5.2 & OD & $\mathrm{E} 1, \mathrm{E} 4, \mathrm{C}$ & 1 \\
\hline & & $\mathrm{EH}$ & $q E H . B-1.5$ & & & & 5 & 2 & 8.4 & OD & $\mathrm{E} 4, \mathrm{E} 5, \mathrm{C}$ & 2 \\
\hline & & $\mathrm{EH}(+)$ & qEH.A-1.6 & 4 & -2 & 7.6 & & & & $D$ & $\mathrm{E} 1, \mathrm{E} 2, \mathrm{E} 3, \mathrm{E} 4, \mathrm{C}$ & $2,5,7$ \\
\hline & & $\mathrm{EH}(+)$ & $q E H . A-1.7$ & 4.5 & -2.1 & 8.5 & & & & $D$ & $\mathrm{E} 1, \mathrm{E} 2, \mathrm{E} 3, \mathrm{C}$ & 5,7 \\
\hline Region 5 & 271.6-292.5 & $\mathrm{PH}$ & qPH.B-5.3 & & & & 4.7 & 3 & 7.2 & OD & $\mathrm{E} 2, \mathrm{E} 4, \mathrm{C}$ & $1,2,3$ \\
\hline \multirow[t]{2}{*}{ Region 8.1} & $136.2-143.3$ & $\mathrm{PH}$ & qPH.B-8.2 & & & & 6.6 & 3.6 & 9.9 & OD & $\mathrm{E} 1, \mathrm{E} 4, \mathrm{E} 5, \mathrm{C}$ & $5,6,7$ \\
\hline & & $\mathrm{EH}$ & $q E H . B-8.2$ & & & & 5.7 & 2.2 & 9.5 & OD & $\mathrm{E} 3, \mathrm{E} 4, \mathrm{C}$ & $5,6,7$ \\
\hline Region 8.2 & $215.7-228.3$ & $\mathrm{EH}(+)$ & qEH.A-8.3 & 4.9 & -2.2 & 9.2 & & & & A & $\mathrm{E} 2, \mathrm{E} 3, \mathrm{E} 4, \mathrm{E} 5, \mathrm{C}$ & 3 \\
\hline \multirow[t]{2}{*}{ Region 9} & $96.5-122.1$ & $\mathrm{PH}$ & qPH.B-9.2 & & & & 6.9 & 4.9 & 10.2 & OD & $\mathrm{E} 2, \mathrm{E} 3, \mathrm{E} 5, \mathrm{C}$ & 1 \\
\hline & & $\mathrm{PH}$ & qPH.B-9.3 & & & & 6.3 & 4.4 & 9.4 & OD & $\mathrm{E} 2, \mathrm{E} 3, \mathrm{E} 4, \mathrm{C}$ & 1 \\
\hline
\end{tabular}

${ }^{\mathrm{a}}$ The genomic regions shown in bold are the ones with pleiotropic effect

${ }^{\text {b} T r a i t s ~ a r e ~ p l a n t ~ h e i g h t ~}(\mathrm{PH})$ and ear height $(\mathrm{EH})$. The plus (" + ") signs within the brackets indicate Chang 7-2 contributed increasing alleles

${ }^{\mathrm{C}} \mathrm{QTL}$ information for the combined analysis

${ }^{\mathrm{d}}$ Degree of dominance: A, additive $\left(\left|d_{i}^{*} / a_{i}^{*}\right| \leq 0.20\right)$; PD, partial dominance $\left(0.20<\left|d_{i}^{*} / a_{i}^{*}\right|<0.80\right) ; \mathrm{D}$, dominance $\left(0.80 \leq\left|d_{i}^{*} / a_{i}{ }^{*}\right|<1.20\right)$; and OD,

overdominance $\left(\left|d_{i}^{*} / a_{i}^{*}\right| \geq 1.20\right)$

${ }^{\mathrm{e}} \mathrm{C}$ Indicates the combined QTL analysis based on the BLUP values across five environments

fHeterosis-associated QTLs reported in previous studies: 1 Ku et al. [43]; 2 Wen et al. [48]; 3 Yang et al. [45]; 4 Wang et al. [18]; 5 Frascaroli et al. [46]; 6 Song et al

[22]; 7 Frascaroli et al. [23]; 8 Li et al. [16]

average $\mathrm{PH}$ of $\mathrm{C} / \mathrm{C}$ plants was 11.7 centimeters higher than that of Z/Z (Fig. 3).

To estimate the degree of dominance, we also compared $\mathrm{PH}$ of the three genotypic classes at qPH.A-1.3 in $\mathrm{BC}_{2} \mathrm{~F}_{2}$ population. The additive effect was 5.85 centimeters. The degree of dominance obtained was 0.11 , which indicated additive gene action (Fig. 3 and Table 6). Collectively, the statistically significant difference of $\mathrm{PH}$ in $\mathrm{BC}_{2} \mathrm{~F}_{1}, \mathrm{BC}_{3} \mathrm{~F}_{1}$ and $\mathrm{BC}_{2} \mathrm{~F}_{2}$ indicated an effect of genotype in the qPH.A-1.3 region on PH phenotype.

\section{Discussion}

\section{Genetic basis of heterosis underlying $\mathrm{PH}$ and $\mathrm{EH}$}

Plant height and ear height are decisive factors to plant density and lodging resistance $[20,40]$. In this study, we studied the genetic basis underlying $\mathrm{PH}$ and $\mathrm{EH}$ with a RIL based design III. In total, 111 QTLs were identified (Additional file 2), which indicates the highly polygenic inheritance pattern underlying $\mathrm{PH}$ and $\mathrm{EH}$. Interestingly, all the eight environmentally stable QTLs for $Z_{2}$ were characterized by OD effects, which is consistent with the

Table 5 Newly developed SSR markers for qPH.A-1.3 region

\begin{tabular}{|c|c|c|c|}
\hline Marker & Forward primer(5'-3') & Reverse primer( $\left(5^{\prime}-3^{\prime}\right)$ & Annealing temperature $\left({ }^{\circ} \mathrm{C}\right)$ \\
\hline MPH72 & CTGGGAAGGAAACCTAAACA & CGACTGAGGACACCTATAGACA & 58 \\
\hline MPH96 & GTTGCCTTGTTCTTGATTCAC & TAGCTGCCAGTGGTACTITTC & 60 \\
\hline MPH1056 & TATCCGCTTTCTTCCCTTCT & ACCGCAACCATTCAACATAC & 58 \\
\hline MPH1042 & CCGCTTCTTCCCTTCTCTT & CCGCAACCATTCAACATACA & 58 \\
\hline MPH1061 & CGCGTAAGTTGTGTGTIITT & TCTTTAGTTGAGGCCATTC & 57 \\
\hline MPH1088 & GCACGCAAGAGAGGAATAGA & AAGAGGGAGGATGAGGATTA & 58 \\
\hline MPH16 & AGGAGCTAGGGATTGAATATG & GAATTGACCCGAATTTCC & 58 \\
\hline MPH1132 & CCTGTCAGAGACAGTTCTC & GAGAGAAGAAAAGGGGTACG & 59 \\
\hline MPH1149 & GAACATACCAGTATGGAAGGA & GACCAAATTGGGACTTAACC & 58 \\
\hline MPH5324 & TCCAAGTGACAGAATAAACTTC & ATCACAAGGGTCATCTTCCG & 58 \\
\hline
\end{tabular}



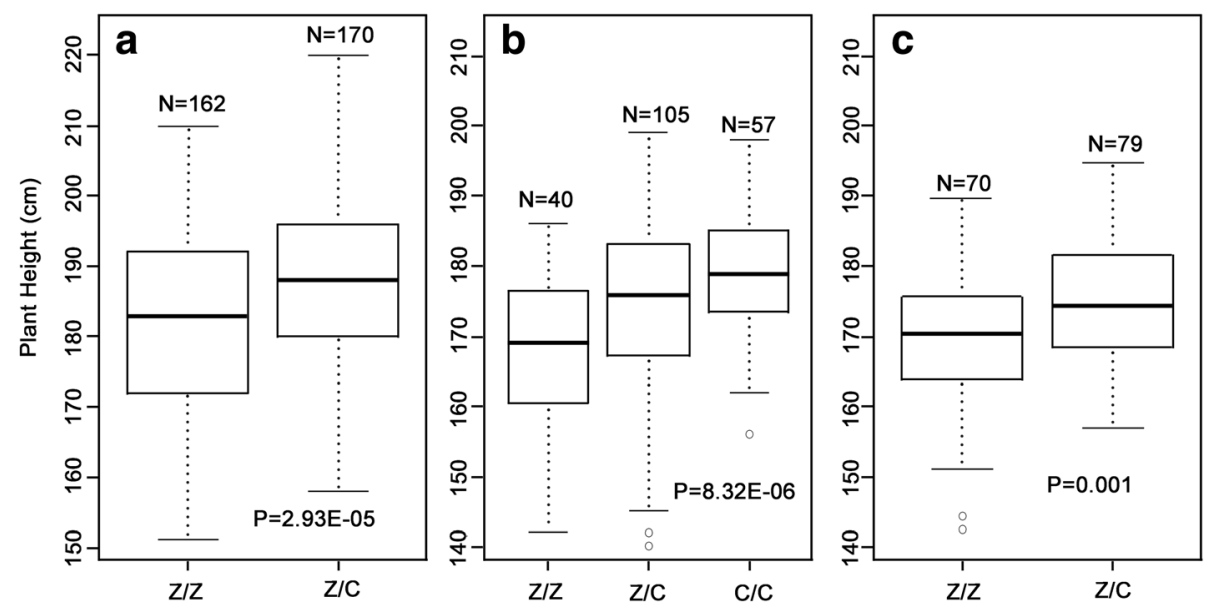

Fig. 3 Validation of $q$ PH.A-1.3 for plant height $(\mathrm{PH})$ in a: $\mathrm{BC}_{2} \mathrm{~F}_{1}$ population, $b: \mathrm{BC}_{2} \mathrm{~F}_{2}$ population, $\mathrm{c}: \mathrm{BC}_{3} \mathrm{~F}_{1}$ population. The three populations were genotyped by using the SSR markers MPH72 and MPH1 149. The distributions and mean values for PH are shown as different genotypic classes: Z/Z homozygous for Zheng 58 haplotype, C/C homozygous for Chang 7-2 haplotype, or Z/C for heterozygous

results in Song et al. [22], suggesting that overdominant QTLs are important contributors to $\mathrm{PH}$ and EH. Nevertheless, QTL showed high overdominance effect may be the result of linked dominant QTLs in repulsion. For example, Graham et al. dissected a major overdominant QTL on chromosome 5 into two dominant QTLs with repulsion-phase linkage [41]. More recently, Li et al. reported that two separate loci with a repulsion linkage could appear as a single locus with an overdominance mode of inheritance [42].

Four of the six environmentally stable QTLs from $\mathrm{Z}_{1}$ exhibited PD or D effects. However, the dominance degree was incompatible in different environments for a given QTL detected for $\mathrm{Z}_{1}$. For example, qPH.A-1.3 showed additive effect (A) in E1, while showed PD effect in other environments (Additional file 2). In addition, this QTL exhibited additive effect (A) in a $\mathrm{BC}_{2} \mathrm{~F}_{2}$ population (Fig. 3 and Table 6). Therefore, we assume that the expression of the degree of dominance might be affected by the environment and/or the genetic background, which will be an interestingly area for further investigation.

\section{Comparison of QTL regions with previous studies}

Due to the high heritability and the ease of its measurement, $\mathrm{PH}$ and $\mathrm{EH}$ have been analyzed in different studies, and common QTLs were reported between individual

Table 6 Gene action of qPH.A-1.3 for plant height (PH) in $\mathrm{BC}_{2} \mathrm{~F}_{2}$ population

\begin{tabular}{|c|c|c|c|c|}
\hline \multirow[t]{2}{*}{ Trait } & \multicolumn{3}{|c|}{ Genotypic classes } & \multirow[t]{2}{*}{ Number } \\
\hline & $\mathrm{Z/Z}$ & $\mathrm{Z} / \mathrm{C}$ & $\mathrm{C} / \mathrm{C}$ & \\
\hline $\mathrm{PH}$ & 167.9 & 174.4 & 179.6 & 202 \\
\hline
\end{tabular}

Genotypic classes obtained by the two markers (MPH72 and MPH1149) flanking $9 P H . A-1.3$ region. Z/Z indicates homozygous for Zheng58, Z/C indicates heterozygous, and $C / C$ indicates homozygous for Chang7-2 populations, which provided valuable information for future studies including their positional cloning or markerassisted selection $[16,43,44]$. The present study identified six genomic regions on four chromosomes, which harbor 14 environmentally stable QTLs for $\mathrm{PH}$ and EH (Fig. 2 and Table 4). Comparison analysis revealed that the detected genomic regions overlapped with previous reported QTLs in terms of $\mathrm{PH}$ and $\mathrm{EH}$, and the percentage of overlapping for each QTL varied from 1.4 - 100\% [16, 18, 22, 23, 45-48] (Fig. 2 and Additional file 4). For example, region 1.2 appeared to be involved in $\mathrm{PH}$ and $\mathrm{EH}$ with $\mathrm{D}$ or OD effects, and it was reported to be a dominant QTL for PH in studies of Frascaroli et al. [23, 46] as well as an additive QTL for EH in study of Yang et al. [45]. The heterosis associated region on chromosome 8 (region 8.1) that showed high individual $R^{2}$ for both $\mathrm{PH}$ and EH was detected as QTL for PH in Frascaroli et al. and Song et al. [22, 23, 46]. Notably, considering the low percentage of overlapping for some QTLs with previous studies, the reliability of overlapped QTLs across different studies deserves for further evaluation.

Region 1.1 contained three tightly linked QTLs for $\mathrm{PH}$, whereas no QTLs were detected for EH. QTLs controlling both $\mathrm{PH}$ and $\mathrm{EH}$ in this region were reported in several studies [18, 22, 45]. Moreover, a QTL for internode length above the uppermost ear was detected by using four RIL populations [47]. Taken together, the lack of QTL for EH in the present study could be ascribed to the following reasons: 1) different allelic variations of the same gene lead to different phenotypes; 2) different genes for $\mathrm{PH}$ and /or EH existed in this QTL region.

\section{The relationship between $\mathrm{PH}$ and $\mathrm{EH}$}

Our results showed that positive correlation coefficients between TCs were observed for $\mathrm{PH}$ and $\mathrm{EH}$ (Table 2). 
$\mathrm{PH}$ is composed of internode number and length both up and below the ear, and EH is composed of internode number and length below the ear. Theoretically, some QTLs might exhibit pleiotropic effects to the two traits. As expected, two overlapped QTLs for PH and EH were identified (Fig. 2 and Table 4). For example, region 1.2 contains one overdominant QTL for PH (qPH.B-1.3), one overdominant QTL for EH (qEH.B-1.5) and one dominant QTL for EH (qEH.A-1.6); region 8.1 contains two overdominant QTLs for PH and EH (qPH.B-8.2 and $q E H . B-8.2)$. However, the possibility of tightly linked QTLs, each controlling PH or EH, could not be ignored.

Notably, some trait-specific QTLs are identified, that is some regions harbor QTLs only for $\mathrm{PH}$ or $\mathrm{EH}$, such as $q P H . B-5.3$ in region for $\mathrm{PH}$ and $q E H . A-8.3$ in region 8.2 for EH. Similar phenomenon was reported in previous studies [47-49]. For example, $\mathrm{Ku}$ et al. reported common and position-specific QTLs affecting internode length at different positions above the uppermost ear [47]. Li et al. demonstrated that the number of leaves above and below the primary ear were under relatively independent genetic control [49]. In conclusion, these results suggested that the underlying genetic basis for $\mathrm{PH}$ and $\mathrm{EH}$ is partially different, which will be an interesting area for further study.

\section{Candidate genes in QTL Regions for PH and/or EH}

To date, over $40 \mathrm{dwarf}$ or semi-dwarf genes have been identified in maize (http://www.maizegdb.org/data_center/phenotype?id=11041/). To identify the candidate genes located within QTLs for PH and/or EH, we firstly analyzed the relationship of maize dwarf or semi-dwarf genes with the detected QTLs for PH and/or EH in this study. Interestingly, four genes were found to locate in QTL regions, including $a n 1, b r d 1$ and $b r 2$ in genomic region 1.2 and ctl1 in region 8.2 (Fig 2 and Additional file 5). AN1 controls a step before ent-kaurene formation, which responds to gibberellins [50]; BRD1 is a homolog encoding brC-6 oxidase, an enzyme that controls the last steps of brassinosteroid biosynthesis [51]. BR2 is an ABC (ATPbinding cassette) transporter belongs to the MDR (multi-drug resistant) class of P-glycoprotein and functions in polar auxin transport as an efflux carrier $[52,53]$. CLT1 was reported to code a BTB domaincontaining protein that comprises 745 amino acids by bioinformatics analysis [54].

Gibberellin (GA) and brassinosteroid (BR) pathways play key roles in the control of plant height $[19,20]$. Thus, we also surveyed the candidate genes responsible for the two pathways in QTL Regions for PH and/or EH. As shown in additional file 5, two GA biosynthesis genes (GRMZM2G117940 and GRMZM2G164090) were found in region 1.1 and region 8.1, respectively. In addition, two GA and one BR pathway genes, including
GRMZM2G059308 for GA biosynthesis, GRMZM2 G114680 for GA signaling and GRMZM2G424075 for brassinosteroid biosynthesis located in region 9. Notably, br2 and GRMZM2G164090 were co-localized with PH and EH QTLs (Additional file 5). A rare SNP mutation in $b r 2$ could affect $\mathrm{PH}$ and $\mathrm{EH}$ by reducing average internode length and internode number [19]. However,the function of gene GRMZM2G164090 on PH and EH has not been characterized. Collectively, those genes are possible candidates for the detected PH and EH QTLs, and detailed studies would be necessary to evaluate their relationship with the QTLs identified in the present study.

\section{Potential utilization of $q P H . A-1.3$ in maize breeding}

Although many dwarf genes for $\mathrm{PH}$ have been cloned, the unacceptable impact on yield production restrained their further utilizations in maize breeding [4]. Therefore, dwarf genes/QTLs with no or very little negative impact on grain yield can be considered as good genetic resources for breeding $[19,20]$. This mapping study identified a QTL-qPH.A-1.3 for PH, which stably showed up in four environments as well as in the combined analysis. Further investigation of three backcross populations $\left(\mathrm{BC}_{2} \mathrm{~F}_{1}, \mathrm{BC}_{2} \mathrm{~F}_{2}\right.$ and $\left.\mathrm{BC}_{3} \mathrm{~F}_{1}\right)$ validated the real existence of this additive QTL and revealed that qPH.A1.3 modified about 10 centimeters of $\mathrm{PH}$. Furthermore, when comparing with the results of QTLs for earweight-related traits which adopted the same genetic materials, including ear row number, ear diameter, number of seeds per row, ear length, one hundred seed weight, ear seed number, ear seed weight and ear weight, overlaps were found in region 1.2, 8.1 and 9. However, no QTL for the ear-weight-related traits was detected in the QTL region of $q$ PH.A-1.3 (Additional file 6) [55]. Collectively, we proposed that $q P H . A-1.3$ may be useful in maize breeding without altering grain yield by using markerassisted selection for two purposes: 1) For energy production and chemical feedstocks, the utilization of Chang 7-2 allele could increase plant height and biomass; 2) For lodging resistance, the Zheng 58 allele could be used to decrease plant height. However, the relationship between qPH.A-1.3 and ear-weight-related traits should be precisely evaluated by advanced segregating populations, such as near-isogenic lines, which is currently underway.

\section{Conclusions}

Of 14 environmentally stable QTLs identified by design III populations, the eight heterosis associated environmentally stable QTLs exhibited OD effects, suggesting that overdominant QTLs were the most important contributors to heterosis for $\mathrm{PH}$ and $\mathrm{EH}$. In addition, a major QTL qPH.A-1.3 was confirmed to modify about 10 centimeters of $\mathrm{PH}$, which may be a desired target for genetic improvement of plant height. 


\section{Additional files}

Additional file 1: Detailed information of the five environments in which the materials were evaluated. (DOC $630 \mathrm{~kb}$ )

Additional file 2: Genotypic data of the Zhengdan 958 RIL population that used in QTL analysis. (XLS 2128 kb)

Additional file 3: QTLs detected for plant height $(\mathrm{PH})$ and ear height $(E H)$ in $Z_{1}$ and $Z_{2}$ in five environments (XLS $45 \mathrm{~kb}$ )

Additional file 4: The genetic linkage map before and after encryption of qPH.A-1.3 region. (DOC $663 \mathrm{~kb}$ )

Additional file 5: Comparison analysis of detected QTLs for plant height $(\mathrm{PH})$ and/or ear height $(\mathrm{EH})$ with previous studies. (XLS $34 \mathrm{~kb}$ )

Additional file 6: Candidate genes in QTL regions. (XLS $30 \mathrm{~kb}$ )

Additional file 7: Comparison of QTLs for PH (plant height) and $\mathrm{EH}$ (ear height) with QTLs for ear-weight-related traits in our previous study. (DOC $3075 \mathrm{~kb})$

\section{Abbreviations}

A: Additive effect; $D^{*}$ : Average degree of dominance; $D$ : Dominance effect; EH: Ear height; MPH: Mid-parent heterosis; OD: Overdominance effect; PD: Partial dominance effect; PH: Plant height; QTL: Quantitative trait locus; RIL: Recombinant inbred line; TC: Testcross

\section{Funding}

This work was supported by the National Key Research and Development Program of China (2016YFD0100801 and 2016YFD0101803).

\section{Availability of data and materials}

The datasets used and/or analyzed during the current study available from the corresponding author on reasonable request.

\section{Authors' contributions}

YRZ conceived the project; QSY and NNF developed the Design III population; $H J L, M Z$ carried out experiments; HJL, HJZ analyzed experimental results; HJL, ZFN and YRZ wrote the manuscript. All authors read and approved the final manuscript.

\section{Competing interests}

The authors declare that they have no conflict of interest.

\section{Consent for publication}

Not applicable.

\section{Ethics approval and consent to participate}

Not applicable.

\section{Publisher's Note}

Springer Nature remains neutral with regard to jurisdictional claims in published maps and institutional affiliations.

Received: 20 January 2017 Accepted: 6 April 2017

Published online: 17 April 2017

\section{References}

1. Rao P, Subbaiah G, Veeraraghavaiah R. Agronomic responses of maize to plant population and nitrogen availability-a review. Int J Plant AnimalEnviron Sci. 2014:4:107-16.

2. Mock JJ, Pearce RB. An ideotype of maize. Euphytica. 1975;24(3):613-23.

3. Duvick DN, Cassman KG. Post-green revolution trends in yield potential of temperate maize in the North-Central United States. Crop Sci. 1999;39(6): 1622-30.

4. Peiffer JA, Romay MC, Gore MA, Flint-Garcia SA, Zhang Z, Millard MJ, et al. The genetic architecture of maize height. Genetics. 2014;196:1337-56.

5. Multani DS, Briggs SP, Chamberlin MA, Blakeslee JJ, Murphy AS, et al. Loss of an MDR transporter in compact stalks of maize br2 and sorghum dw3 mutants. Science. 2003;302:81-4
6. Spray CR, Kobayashi M, Suzuki Y, et al. The dwarf-1 (dt) Mutant of Zea mays blocks three steps in the gibberellin-biosynthetic pathway. Proc Natl Acad Sci U S A. 1996;93(19):10515-8.

7. Fujioka $\mathrm{S}$, Yamane $\mathrm{H}$, Spray $\mathrm{CR}$, et al. Qualitative and quantitative analyses of gibberellins in vegetative shoots of normal, dwarf-1, dwarf-2, dwarf-3, and dwarf-5 seedlings of Zea mays L. Plant Physiol. 1988;88(4):1367-72.

8. Winkler RG, Helentjaris T. The maize Dwarf3 gene encodes a cytochrome P450-mediated early step in Gibberellin biosynthesis. Plant Cell. 1995;7(8): 1307-17.

9. Lawit SJ, Wych HM, Xu D, et al. Maize DELLA proteins dwarf plant8 and dwarf plant9 as modulators of plant development. Plant Cell Physiol. 2010; 51(11):1854-68.

10. Winkler RG, Freeling M. Physiological genetics of the dominant gibberellinnonresponsive maize dwarfs, Dwarf8 and Dwarf9. Planta. 1994;193(3):341-8.

11. Multani DS, Briggs SP, Chamberlin MA, et al. Loss of an MDR transporter in compact stalks of maize br2 and sorghum dw3 mutants. Science. 2003; 302(5642):81-4

12. Hartwig T, Chuck GS, Fujioka S, et al. Brassinosteroid control of sex determination in maize. Proc Natl Acad Sci U S A. 2011:108(49):19814-9.

13. East EM. Inbreeding in corn. Report of the Connecticut Agricultural Experiment Station. 1908. p. 419-28.

14. Helentjaris T, Slocum M, Wright S, Schaefer A, Nienhuis J. Construction of genetic linkage maps in maize and tomato using restriction fragment length polymorphisms. Theor Appl Genet. 1986;72:761-9.

15. Cai H, Chu Q, Gu R, et al. Identification of QTLs for plant height, ear height and grain yield in maize (Zea mays L.) in response to nitrogen and phosphorus supply. Plant Breed. 2012;131(4):502-10.

16. Li X, Zhou Z, Ding J, Wu Y, Zhou B, Wang R, Ma J, Wang S, Zhang X, Xia Z, Chen J, Wu J. Combined linkage and association mapping reveals QTL and candidate genes for plant and ear height in maize. Front Plant Sci. 2016;7: 833. doi:10.3389/fpls.2016.00833.

17. Peiffer JA, Romay MC, Gore MA, et al. The genetic architecture of maize height. Genetics. 2014;196(4):1337-56.

18. Wang $Y, X u J$, Deng $D$, et al. A comprehensive meta-analysis of plant morphology, yield, stay-green, and virus disease resistance QTL in maize (Zea mays L.). Planta. 2016;243(2):459-71.

19. Xing A, Gao Y, Ye L, et al. A rare SNP mutation in Brachytic2 moderately reduces plant height and increases yield potential in maize. J Exp Bot. 2015; 66(13):3791-802.

20. Teng $F$, Zhai $L$, Liu $R$, et al. ZmGA3ox2, a candidate gene for a major QTL, qPH3. 1, for plant height in maize. Plant J. 2013;73(3):405-16.

21. Shull GH. The composition of a field of maize. J Hered. 1908;1:296-301.

22. Song FW, Peng HR, Liu T, et al. Heterosis for plant height and ear position in maize revealed by quantitative trait loci analysis with triple testcross design. Acta Agron Sin. 2011;37(7):1186-95.

23. Frascaroli E, Canè MA, Landi P, Pea G, Gianfranceschi L, Villa M, et al. Classical genetic and quantitative trait loci analyses of heterosis in a maize hybrid between two elite inbred lines. Genetics. 2007;176(1):625-44.

24. Tang JH, Ma XQ Teng WT, et al. Detection of quantitative trait loci and heterotic loci for plant height using an immortalized $\mathrm{F}_{2}$ population in maize. Chin Sci Bull. 2007:52(4):477-83.

25. Lu H, Romero-Severson J, Bernardo R. Genetic basis of heterosis explored by simple sequence repeat markers in a random-mated maize population. Theor Appl Genet. 2003;107(3):494-502.

26. Comstock RE, Robinson HF. Estimation of average dominance of genes. In: Gowen JW, editor. Heterosis. Ames.: ISU Press; 1952. p. 494-516.

27. Stuber CW, Lincoln SE, Wolff DW, Helentjaris T, Lander ES. Identification of genetic factors contributing to heterosis in a hybrid from two elite maize inbred lines using molecular markers. Genetics. 1992;132:823-39.

28. Cockerham CC, Zeng ZB. Design III with marker loci. Genetics. 1996;143: 1437-56.

29. Du C, Cao C, Cao Q, Bi M, Dong Z, Zhang F. The breeding and application of maize hybrid Zhengdan 958. Maize Sci. 2006;14:43-5. doi:10.3969/j.issn. 1005-0906.2006.06.011.

30. Melchinger AE, Utz HF, Piepho HP, Zeng ZB, Schön CC. The role of epistasis in the manifestation of heterosis: a systems-oriented approach. Genetics. 2007;177(3):1815-25.

31. Knapp SJ, Stroup WW, Ross WM. Exact confidence intervals for heritability on a progeny mean basis. Crop Sci. 1985;25(1):192-4.

32. Churchill GA, Doerge RW. Empirical threshold values for quantitative trait mapping. Genetics. 1994;138:963-71. 
33. Ganal M. W, Durstewitz, G, Polley, A, Bérard, A, Buckler, E S, Charcosset, A, et al. A large maize (Zea mays L.) SNP genotyping array: development and germplasm genotyping, and genetic mapping to compare with the B73 reference genome. PLoS One. 2011;6(12):e28334.

34. Wu Y, Bhat P. R, Close, T J, Lonardi, S. Efficient and accurate construction of genetic linkage maps from the minimum spanning tree of a graph. PLoS Genet. 2008;4(10):e1000212.

35. Zeng Z-B. Precision mapping of quantitative trait loci. Genetics. 1994;136(4): 1457-68.

36. Wang S, Basten CJ, Zeng ZB. Windows QTL cartographer version 2.5. Statistical genetics. Raleigh: North Carolina State University; 2005.

37. Li Q, Wan J. SSRHunter: development of a local searching software for SSR sites. Hereditas. 2005;27(5):808-10.

38. Zhang D, Liu Y, Guo Y, et al. Fine-mapping of 9 Rfg2, a QTL for resistance to Gibberella stalk rot in maize. Theor Appl Genet. 2012;124(3):585-96.

39. Wu JW, Liu C, Shi YS, Song YC, Zhang GY, Ma ZY, et al. QTL analysis of plant height and ear height in maize under different water regimes. J Plant Genet Res. 2005;6:266-71.

40. Tang J, Teng W, Yan J, Ma X, Meng Y, Dai J, Li J. Genetic dissection of plant height by molecular markers using a population of recombinant inbred lines in maize. Euphytica. 2007;155:117-24.

41. Graham GI, Wolff DW, Stuber CW. Characterization of a yield quantitative trait locus on chromosome five of maize by fine mapping. Crop Sci. 1997; 37(5):1601-10.

42. Li X, Li X, Fridman E, Tesso T. T, Yu, J. Dissecting repulsion linkage in the dwarfing gene Dw3 region for sorghum plant height provides insights into heterosis. Proc Natl Acad Sci U S A. 2015;112(38):11823-8.

43. Yang GH, Dong YB, Li YL, et al. Integrative detection and verification of QTL for plant traits in two connected RIL populations of high-oil maize. Euphytica. 2015;206(1):203-23.

44. Zaidi PH, Rashid Z, Vinayan MT, et al. QTL mapping of agronomic waterlogging tolerance using recombinant inbred lines derived from tropical maize (Zea mays L.) germplasm. PLoS One. 2015;10(4):e0124350.

45. Yang XJ, Lu M, Zhang SH, et al. QTL mapping of plant height and ear position in maize (Zea mays L.). Hereditas. 2008;30(11):1477-86.

46. Frascaroli E, Cane MA, Pe ME, et al. QTL detection in maize testcross progenies as affected by related and unrelated testers. Theor Appl Genet. 2009;1 18(5): 993-1004.

47. Ku L, Cao L, Wei X, Su H, Tian Z, Guo S, Zhang L, Ren Z, Wang X, Zhu Y, Li G, Wang Z, Chen Y. Genetic dissection of internode length above the uppermost ear in four RIL populations of maize (Zea mays L.). Genes Genomes Genet. 2015;5(2):281-9. doi:10.1534/g3.114.016378DOl:10.1534/ g3.114.016378\#_blank.

48. Weng J, Xie C, Hao Z, et al. Genome-wide association study identifies candidate genes that affect plant height in Chinese elite maize (Zea mays L.) inbred lines. PLoS One. 2011;6(12):e29229.

49. Li D, Wang $X$, Zhang $X$, et al. The genetic architecture of leaf number and its genetic relationship to flowering time in maize. New Phytol. 2016;210(1): 256-68

50. Bensen R. J, Johal, G S, Crane, V C, Tossberg, J T, Schnable, P S, Meeley, R B and Briggs, S P. Cloning and characterization of the maize An1 gene. Plant Cell. 1995;7:75-84

51. Makarevitch I, Thompson A, Muehlbauer GJ, et al. Brd1 gene in maize encodes a brassinosteroid C-6 oxidase. PLoS One. 2012;7(1):e30798.

52. Noh B, Murphy AS, Spalding EP. Multidrug resistance-like genes of arabidopsis required for auxin transport and auxin-mediated development. Plant Cell. 2001; 13:2441-54.

53. Multani DS, Briggs SP, Chamberlin MA, Blakeslee JJ, Murphy AS, Johal GS. 2003. Loss of an MDR transporter in compact stalks of maize br2 and sorghum dw3 mutants. Science. 2003;302:81-4.

54. Gao JX, Liu T, Chen J. Insertional mutagenesis and cloning of the gene required for the biosynthesis of the non-host-specific toxin in Cochliobolus lunatus that causes maize leaf spot. Phytopathology. 2014;104(4):332-9.

55. Li H, Yang Q, Gao L, Zhang M, Ni Z, Zhang Y. Identification of heterosisassociated stable QTLs for ear-weight-related traits in an elite maize hybrid Zhengdan 958 by Design III. Front Plant Sci. 2017;8:561. doi:10.3389/fpls. 2017.00561 .

\section{Submit your next manuscript to BioMed Central and we will help you at every step:}

- We accept pre-submission inquiries

- Our selector tool helps you to find the most relevant journal

- We provide round the clock customer support

- Convenient online submission

- Thorough peer review

- Inclusion in PubMed and all major indexing services

- Maximum visibility for your research

Submit your manuscript at www.biomedcentral.com/submit

) Biomed Central 